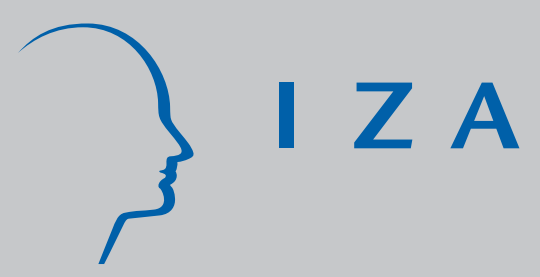

IZA DP No. 3498

Firms' Ethics, Consumer Boycotts, and Signalling

Amihai Glazer

Vesa Kanniainen

Panu Poutvaara

May 2008 


\title{
Firms' Ethics, Consumer Boycotts, and Signalling
}

\author{
Amihai Glazer \\ University of California, Irvine \\ Vesa Kanniainen \\ University of Helsinki \\ Panu Poutvaara \\ University of Helsinki \\ and IZA
}

Discussion Paper No. 3498
May 2008

IZA

P.O. Box 7240

53072 Bonn

Germany

Phone: +49-228-3894-0

Fax: +49-228-3894-180

E-mail: iza@iza.org

\begin{abstract}
Any opinions expressed here are those of the author(s) and not those of IZA. Research published in this series may include views on policy, but the institute itself takes no institutional policy positions.

The Institute for the Study of Labor (IZA) in Bonn is a local and virtual international research center and a place of communication between science, politics and business. IZA is an independent nonprofit organization supported by Deutsche Post World Net. The center is associated with the University of Bonn and offers a stimulating research environment through its international network, workshops and conferences, data service, project support, research visits and doctoral program. IZA engages in (i) original and internationally competitive research in all fields of labor economics, (ii) development of policy concepts, and (iii) dissemination of research results and concepts to the interested public.
\end{abstract}

IZA Discussion Papers often represent preliminary work and are circulated to encourage discussion. Citation of such a paper should account for its provisional character. A revised version may be available directly from the author. 


\section{ABSTRACT \\ Firms' Ethics, Consumer Boycotts, and Signalling*}

This paper develops a theory of consumer boycotts. Some consumers care not only about the products they buy but also about whether the firm behaves ethically. Other consumers do not care about the behavior of the firm but yet may like to give the impression of being ethical consumers. Consequently, to affect a firm's ethical behavior, moral consumers refuse to buy from an unethical firm. Consumers who do not care about ethical behavior may join the boycott to (falsely) signal that they do care. In the firm's choice between ethical and unethical behavior, the optimality of mixed and pure strategies depends on the cost of behaving ethically. In particular, when the cost is (relatively) low, ethical behavior arises from a prisoners' dilemma as the firm's optimal strategy.

JEL Classification: M14, D43

Keywords: firm's ethical code, consumer morality, boycotts

Corresponding author:

Panu Poutvaara

Department of Economics

University of Helsinki

P.O. Box 17 (Arkadiankatu 7)

00014 Helsinki

Finland

E-mail: panu.poutvaara@helsinki.fi

\footnotetext{
*Prepared for the CESifo Ethics and Economics conference in Munich, February 7-9, 2008. We are grateful to the participants, especially to Werner Güth, for many helpful comments. An earlier version was presented at the NORIO VI Conference in Stockholm, June 1-2, 2007 and at the EBEN Conference on Business Ethics, Leuven September 19-20, 2007. Vesa Kanniainen acknowledges the financial support from Yrjö Jahnsson foundation.
} 


\section{Introduction}

A firm deviating from an accepted social norm like environmental protection, sound personnel policy, or avoidance of child labor, may risk punishment by consumers. Examples of such punishments are many. Shell Oil suffered damage to its image from the military action of the Nigerian government against domestic protests aimed at protecting the delta of its river. Nestle suffered from lost reputation after selling inappropriate milk to pregnant mothers in developing countries. In 2005, an Estonian ship was caught releasing waste into the Baltic Sea. After the passengers' initiative to boycott the owner, it quickly announced a policy change, pledging to safely release waste into containers. The plan of the firm producing the British condiment HP sauce to move production to the Netherlands caused a consumer boycott in Britain. While these examples may suggest that a consumer boycott is a tool used to empower the disadvantaged, it is important to highlight that consumer boycotts can also be used to pursue conflicting ethical aims. During the apartheid regimes, Rhodesia and South Africa were boycotted by the opponents of racism. In Nazi Germany, consumer boycotts were used to persecute Jews. During the recent row about Danish cartoons that some Muslims found offensive, the Danish firm Arla was first boycotted in several Islamic countries, which then triggered a counter boycott among those western consumers regarding the initial boycott as unfair.

A person who joins a consumer boycott is typically willing to pay a higher price for a good produced by a firm not boycotted. Moreover, those organizing the boycott often want to see other consumers join. The internet and other modern means of communication provide consumers with new instruments to influence the ethical behavior of other producers (Andersen, 1999). ${ }^{1}$ The consumers' concerns may induce a firm to devote attention to its image. ${ }^{2}$

\footnotetext{
${ }^{1}$ John, Klein and Smith (2002) and Klein, Smith and John (2004) explore the motivations for consumer boycotts.

${ }^{2}$ Consumers' influence can be thought to be the greatest in industries where products are not too differentiated and where competition is severe. Those features can be expected to be measured by price elasticities. Elastic demand points to high substitutability and a low switching cost. Research supports the proposition that consumers can influence firms, see Morales (2005). Cronberg (1986) analyzes consumers' influence on new technology. Reasons for why boycotts arise are studied by Klein, Mith, and John (2004). Information on how consumers react to other matters than the price - a firm's image - can apparently be based on case studies only. Stock prices and consumer prices can there be helpful indicators.
} 
Indeed, the internet home pages of many firms describe their work in helping development projects and controlling environmental damage. ${ }^{3}$

Our paper analyzes a model in which competing firms produce identical products but can choose their corporate ethics, differentiating their image among consumers. Consumers observe the behavior of firms. Moral consumers avoid buying from a firm which violated some ethical position. We ask when amoral consumers join a boycott initiated by the moral ones. They may join a boycott because of the private benefit of pretending to have a moral stance. We ask how firms behave under the threat of a boycott. We examine in particular whether a boycott can effectively direct corporate ethics and how competition determines the market outcome. ${ }^{4}$ The existing literature is meager. Some papers study corporate ethics, but only a few study consumers' actions. Baron (2002) analyzes individuals deciding when and how much to boycott the firm. The action reveals information which represents a public good. Innes (2006) examines strategic interactions between non-identical duopolistic firms and an environmental organization. There are several differences when compared with our paper. In our paper, consumers are heterogeneous and the game is between the rival firms, not between the firms and the environmental organization. In Innes (2006), the combined sales by the two firms are constant. In our model instead, the sales are endogenous. If both firms pollute the moral consumers do not buy from either in our model. In Innes (2006), only one of the firms may be subject of a boycott. ${ }^{5}$ In our paper, the efficiency of a boycott is determined by the moral reaction of consumers and the cost imposed on consumers who do not join the boycott. For concreteness, we shall say that a firm behaves ethically if and only if it makes an investment which reduces its profits but is valued by moral consumers and hence attracts customers. What makes the problem non-trivial is the joint consideration of consumer and firm behavior.

\footnotetext{
${ }^{3}$ Switching costs, which may especially appear when transaction costs make consumers commit to some products, are analyzed by Klemperer (1995). See also Antheon, Camarero and Carrero (2007).

${ }^{4} \mathrm{~A}$ firm can respond to a boycott by playing tough or weak, depending on how much it values a good image. Corporate social responsibility, CSR, has grown to a highly debated issue, initiated long time ago by Friedman (1970) who defended the profit maximization target. The strategy of a firm may result in a particular reputation and may influence the success or failure of a future boycott. We ignore such reputation building in the current paper.

${ }^{5}$ Kanniainen and Pietarila (2006) analyze consumers' influence on the ethical choice of firms but abstract from boycotts.
} 
Section 2 of the paper introduces the ethical preferences of consumers and the firms' strategies. Section 3 analyzes the market equilibrium when the firms' ethical codes differ. Section 4 considers the optimal pure strategies; Section 5 considers mixed strategies. Section 6 shows that the ethical behavior of firms may arise from a prisoners' dilemma. Section 7 concludes.

\section{Assumptions}

\section{$2.1 \quad$ Firms}

We cast the analysis in terms of a duopoly market where two firms compete for customers. The products (or services) are physically identical but the production processes can differ; we can say that production is polluting or not.

There are two periods. In period 1, each firm decides on whether to pollute; it invests or not say, in pollution abatement. The cost of abatement can differ across firms. We consider the cases where mixed strategies or alternatively pure strategies are optimal. In period 2, each firm's pollution becomes common knowledge, and each consumer decides at which firm to buy.

\subsection{Ethical preferences of consumers}

People differ in their attitudes to pollution, and some may find it valuable to misrepresent their hidden preferences. There are two types of consumers. An $a$-type has moral preferences; a $b$-type does not. ${ }^{6}$ The mass of $a$-type consumers is $n$; the mass of $b$-type consumers is scaled to $1 .^{7}$ Each consumer buys at most one unit of the good. In the two groups, consumers are indexed in decreasing order on $i \epsilon[0, n]$ and $j \epsilon[0,1]$ with respect to their basic willingness to pay for the product. Consumers $i=0$ and $j=0$ have the highest basic willingness to pay for the product, say $\beta$ in each group; consumers $i=n$

\footnotetext{
${ }^{6}$ The origin of ethical preference lies beyond our scope. A natural source is that the preferences are created by evolutionary mechanisms among human beings becoming integrated into a social contract, cf. Binmore (1998). It is appropriate to think that the ability to commit to a social norm and the option to participate in a boycott develop like a social meme introduced by Dawkins (1976) and elaborated by Blackmore (1999).

${ }^{7}$ The population hence consists of a mixture of individuals of homo moralis and homo oeconomicus types.
} 
and $j=1$ have zero willingness to pay for it. The willingness to pay by the remaining consumers is uniformly distributed on $(0, \beta)$ in both groups. To illustrate, and ignoring moral and reputational effects for the moment, the utility from consumption by consumers, say $k$ and $l$, are given by indirect utility functions $u_{k}=\beta(n-k)-p$ and $u_{k}=\beta(1-k)-p$ where $p$ is the market price.

The products become differentiated if one firm pollutes while the other does not. In the social context, inviduals may view it important to be considered moral so as to avoid exclusion from particular social groups, loss of friendship, and even barriers in the marriage market. We let $b>0$ denote the cost imposed on a consumer who does not join the boycott. This can be thought of as a social pressure, commonly observed.

\section{$3 \quad$ Equilibrium with differing pure strategies}

We shall consider three different combinations of investment in abatement: no firm invests, both firms invest, or only one does. As we eventually have to determine the outcome of the investment game under various strategies, it is most illuminating to start with the case of two pure strategies. In this section therefore, we consider the case where one of the firms invests, thereby incurring a fixed cost $c$, while the other does not invest. Occasionally we allow for differences in the costs for reasons which will become clear. In the market, the products of the firms, though perfect substitutes in consumption, differ with different images of their producers. Some consumers will then switch from buying the product of the firm which pollutes, say $L$, to buying from the firm which does not pollute, say $H$. More specifically, the boycotting high-moral consumers abstain from buying at firm $L$ and buy only at firm $H$. Since in equilibrium not all may buy, we denote the number of active high-moral buyers by $x_{h}$. The number of low-moral consumers who stay at firm $L$ is denoted by $x_{l}$. Some of the low types, however, switch to the $H$ firm in order to (falsely) signal high morality. Their number is denoted by $x_{m}$.

Equilibrium We denote the resulting price at the ethical firm by $p_{H}$ and the price at the non-ethical firm by $p_{L}$. The resulting market equilibrium has the following structure. From the definition of the marginal moral consumer 
$x_{h}$, we know that the equilibrium price at firm $H$ satisfies

$$
\beta\left(1-\frac{x_{h}}{n}\right)=p_{H} \cdot{ }^{8}
$$

We can of course have a market equilibrium where no low-moral consumer switches to firm $H$. However, to make the analysis interesting, we assume that the benefit from signalling is sufficient so that some, i.e. $x_{m}$, do. The marginal low-moral consumer must be indifferent between the two markets. Thus, prices must satisfy

$$
\beta\left(1-x_{m}\right)-p_{H}=\beta\left(1-x_{m}\right)-b-p_{L},
$$

where, to recall, $b$ is the social pressure when a consumer buys at firm $L$. Therefore,

Lemma 1. The price difference arises from the cost of social pressure,

$$
p_{H}-p_{L}=b .^{9}
$$

The marginal low-moral consumer (with an index $j=x_{m}+x_{l}$ ) is indifferent between buying at firm $L$ or buying nothing. Thus, his net utility is

$$
\beta\left(1-x_{m}-x_{l}\right)-b=p_{L} .
$$

In the Cournot model, firms decide on their outputs allowing the prices to adjust. ${ }^{10}$ Denote the outputs of the two firms by $y_{H}$ and $y_{L}$. Then,

$$
y_{H}=x_{h}+x_{m}, \quad y_{L}=x_{l} .
$$

Thus, the number of active moral buyers is $x_{h}=y_{H}-x_{m}$. To solve for the prices, we first determine the number of signalling consumers. Using $p_{H}-p_{L}=b$,

$$
\beta\left(1-\frac{y_{H}}{n}+\frac{x_{m}}{n}\right)-\beta\left(1-x_{m}-x_{l}\right)+b=b .
$$

${ }^{8}$ Therefore, not all moral consumers buy. They all buy only if $x_{h}=n$, making $p_{H}=0$. Otherwise, $x_{h}<n$.

${ }^{9}$ We notice that all low-moral types are indifferent between the two markets as the social cost of pressure just matches the price difference. Each firm chooses its output knowing the consumers' behavior.

${ }^{10}$ The behavior of firms in duopolistic markets has been subject to some debate, cf. Kreps and Sheinkman (1983). Güth (1993) shows how quantity competition can be justified without the complexities discussed by the earlier literature. 
This gives for the number of signalling consumers,

$$
x_{m}=\frac{y_{H}-n y_{L}}{1+n} .
$$

Then, the profits are

$$
\begin{aligned}
\pi_{H} & =y_{H} p_{H}-c \\
& =y_{H}\left(\beta-\beta \frac{y_{H}+y_{L}}{1+n}\right)-c \\
\pi_{L} & =y_{L} p_{L} \\
& =y_{L}\left[\beta-\beta \frac{y_{H}+y_{L}}{1+n}-b\right]
\end{aligned}
$$

From the first-order conditions we can rewrite

$$
\begin{aligned}
& \frac{\partial \pi_{H}}{\partial y_{H}}=\beta\left(1-\frac{y_{L}}{1+n}\right)-2 \beta \frac{y_{H}}{1+n} \\
& \frac{\partial \pi_{L}}{\partial y_{L}}=\beta-\beta \frac{y_{H}}{1+n}-b-2 \beta \frac{y_{L}}{1+n} .
\end{aligned}
$$

Solving for the Nash-Cournot equilibrium, the first of those conditions gives:

or

$$
\frac{2 \beta}{1+n} y_{H}=\beta\left(1-\frac{y_{L}}{1+n}\right)
$$

$$
y_{H}=\frac{1+n}{2}-\frac{y_{L}}{2} .
$$

We then obtain the solutions for the outputs:

Proposition 1. The Cournot-Nash equilibrium is given by the market shares

$$
\begin{aligned}
& y_{L}=\frac{(1+n)}{3}-\frac{2(1+n) b}{3 \beta}=\frac{(1+n)(\beta-2 b)}{3 \beta} \\
& y_{H}=\frac{(1+n)}{3}+\frac{(1+n) b}{3 \beta}=\frac{(1+n)(\beta+b)}{3 \beta} .
\end{aligned}
$$


The non-polluting firm benefits from the incentive of the less moral consumers who mimic the moral ones. Similarly, social pressure on the amoral consumers benefits this firm while the unethical firm suffers from a loss of customers.

Noticing that the signalling benefit or the social pressure may differ between products, we state

Corollary 1. The economic effect of a boycott is small when the boycott is directed at products which are less useful for signalling reasons, that is, where the social punishment is low.

Solving next for the number of mimicking customers,

$$
\begin{aligned}
x_{m} & =\frac{y_{H}-n y_{L}}{1+n} \\
& =\frac{1-n}{3}+\frac{(1+2 n) b}{3 \beta} .
\end{aligned}
$$

Lemma 2 The number of mimicking customers is determined by the signalling benefit - the cost of social pressure - relative to the basic willingness to pay by the consumers.

Thus, a consumer boycott by moral (non-opportunistic) people induces some opportunistic amoral people to take advantage of the signalling benefit, making the consumer market in the aggregate behave more morally. The smaller is the cost of social pressure relative to the basic willingness to pay, the less effective is the boycott.

We next solve for the prices, starting those faced by the non-moral consumers:

$$
\begin{aligned}
p_{L} & =\beta\left(1-x_{m}-x_{l}\right)-b \\
& =\frac{\beta-2 b}{3} .
\end{aligned}
$$


Therefore,

$$
\begin{aligned}
p_{H} & =p_{L}+b \\
& =\frac{\beta+b}{3} .
\end{aligned}
$$

The equilibrium studied above is characterized by profits $\left(\pi_{H}^{H L}, \pi_{L}^{H L}\right)$ which can be calculate as

$$
\begin{aligned}
\pi_{H}^{H L} & =p_{H} y_{H}-c \\
& =\frac{(\beta+b)^{2}(1+n)}{9 \beta}-c \\
\pi_{L}^{H L} & =p_{L} y_{L} \\
& =\frac{(\beta-2 b)^{2}(1+n)}{9 \beta}
\end{aligned}
$$

\section{Firms' ethical decisions}

\subsection{Equilibrium with mixed strategies}

To examine the conditions for an equilibrium with mixed strategies, call the firms $A$ and $B$. Assume that the investment is not observable when undertaken but that in the production stage, consumers observe whether a firm pollutes. Now, the firms can for competitive reasons randomize their investments and we start by studying the mixed strategy equilibrium. We then work out whether and when a pure strategy - and which one can arise in equilibrium.

Let $q_{A}, q_{B}$ denote the probabilities of investing. The expected profits are

$$
\begin{aligned}
& E\left[\pi_{A}\right]=q_{A}\left[q_{B} \pi_{A}^{H H}+\left(1-q_{B}\right) \pi_{A}^{H L}\right]+\left(1-q_{A}\right)\left[q_{B} \pi_{A}^{L H}+\left(1-q_{B}\right) \pi_{A}^{L L}\right] \\
& E\left[\pi_{B}\right]=q_{B}\left[q_{A} \pi_{B}^{H H}+\left(1-q_{A}\right) \pi_{B}^{L H}\right]+\left(1-q_{B}\right)\left[q_{A} \pi_{B}^{H L}+\left(1-q_{A}\right) \pi_{B}^{L L}\right] .
\end{aligned}
$$

The expected profits are linear in the probabilities. A (mixed) Nash equilibrium in terms of the optimal probabilities must satisfy

$$
\frac{\partial E\left[\pi_{A}\right]}{\partial q_{A}}=0, \frac{\partial E\left[\pi_{B}\right]}{\partial q_{B}}=0 .
$$


The first-order conditions allow to solve

$$
\begin{aligned}
q_{B} & =\frac{-\left(\pi_{A}^{H L}-\pi_{A}^{L L}\right)}{\left(\pi_{A}^{H H}-\pi_{A}^{L H}\right)-\left(\pi_{A}^{H L}-\pi_{A}^{L L}\right)} \\
& =\frac{1}{1-\frac{\left(\pi_{A}^{H H}-\pi_{A}^{L H}\right)}{\left(\pi_{A A}^{H L}-\pi_{A}^{L L}\right)}} \\
q_{A} & =\frac{-\left(\pi_{B}^{L H}-\pi_{B}^{L L}\right)}{\left(\pi_{B}^{H H}-\pi_{B}^{H L}\right)-\left(\pi_{B}^{L H}-\pi_{B}^{L L}\right)} \\
& =\frac{1}{1-\frac{\left(\pi_{B}^{H H}-\pi_{B}^{H L}\right)}{\left(\pi_{B}^{L H}-\pi_{B}^{L L}\right)}} .
\end{aligned}
$$

These conditions represent a Nash equilibrium without a dominating strategy. An interior solution, $0<q_{A}<1,0<q_{B}<1$, requires that

$$
\frac{\left(\pi_{A}^{H H}-\pi_{A}^{L H}\right)}{\left(\pi_{A}^{H L}-\pi_{A}^{L L}\right)}<0, \quad \frac{\left(\pi_{B}^{H H}-\pi_{B}^{H L}\right)}{\left(\pi_{B}^{L H}-\pi_{B}^{L L}\right)}<0 .
$$

Therefore, before we can address these conditions, we need to study the pure strategies to find out the profit levels.

\subsection{When both firms choose the same pure strategy}

In this section, we allow for the costs of investment, $c_{A}, c_{B}$, to differ.

\subsubsection{Neither firm invests}

It is also possible that one strategy dominates for both firms. When it is optimal to choose $q_{A}=q_{B}=0$, not investing represents the dominant strategy. Now one group of customers - boycotters - leaves the market, i.e. the total market size is squeezed to 1 , there is one price and the firms share the customers on an equal basis.

The profits are then

$$
\pi_{A}^{L L}=p_{A} y_{L}, \quad \pi_{B}^{L L}=p_{B} y_{L} .
$$


Necessary conditions ${ }^{11}$ for no investing representing a dominant strategy are

$$
\pi_{A}^{H H}<\pi_{A}^{L L}, \pi_{B}^{H H}<\pi_{B}^{L L} .
$$

To solve, the marginal customer has zero utility

$$
\beta\left(1-y_{A}-y_{B}\right)-b-p_{L}=0
$$

Profits are

$$
\begin{aligned}
& \pi_{A}=\left[\beta\left(1-y_{A}-y_{B}\right)-b\right] y_{A} \\
& \pi_{B}=\left[\beta\left(1-y_{A}-y_{B}\right)-b\right] y_{B}
\end{aligned}
$$

Solving for the Nash-Cournot equilibrium, we find

$$
y_{B}=\frac{1}{3}\left(\frac{\beta-b}{\beta}\right), \quad y_{B}=\frac{1}{3}\left(\frac{\beta-b}{\beta}\right)
$$

The price can be solved as

$$
p_{L}=\frac{1}{3}(\beta-b)
$$

Profits in the no investment equilibrium are

$$
\pi_{A}^{L L}=\pi_{B}^{L L}=\frac{1}{9} \frac{(\beta-b)^{2}}{\beta} .
$$

\subsubsection{Both firms invest}

When it is optimal to choose $q_{A}=q_{B}=1$, investing is the dominant strategy. Profits are then

$$
\pi_{A}^{H H}=p_{H} q_{H}-c_{A}, \quad \pi_{B}^{H H}=p_{H} q_{H}-c_{B} .
$$

For completeness, we allowed for different costs. The outcome is a symmetric Cournot equilibrium. This equilibrium can arise if the cost saving $c_{i}$

\footnotetext{
${ }^{11}$ These conditions are not, however, sufficient, as a prisoners' dilemma to be studied below arises under these same conditions (strengthened by some others) with $q_{A}=q_{B}=1$ representing the dominating strategy.
} 
is small for both firms. ${ }^{12}$ Necessary conditions for investment representing a dominant strategy are

$$
\pi_{A}^{H H}>\pi_{A}^{L L}, \pi_{B}^{H H}>\pi_{B}^{L L}
$$

To solve for the market shares, we notice first that the total mass of potential customers in the market in this case is $1+n$ and the two firms share these customers. The firms now face a less steep market demand as the mass of potential customers is increased. Denoting the total amount of buying customers by $x_{H H}$, it must hold that the last buyer is indifferent between buying and not buying. As his willingness to pay has to match with the market price, it must hold,

$$
\beta\left(1-\frac{x_{H H}}{1+n}\right)=p_{H} .
$$

As the market is shared, we have that

$$
x_{H H}=x_{A}+x_{B}
$$

The profits are

$$
\begin{aligned}
\pi_{A}^{H H} & =\beta\left(1-\frac{x_{A}+x_{B}}{1+n}\right) x_{A}-c_{A} \\
\pi_{B}^{H H} & =\beta\left(1-\frac{x_{A}+x_{B}}{1+n}\right) x_{B}-c_{B} .
\end{aligned}
$$

Using the first-order conditions, we obtain for the outputs,

$$
x_{A}=\frac{1+n}{3}=x_{B} .
$$

Then, when both firms invest, the equilbrium profits are

$$
\begin{aligned}
\pi_{i}^{H H} & =\beta\left(1-\frac{x_{A}+x_{B}}{1+n}\right)\left(\frac{1+n}{3}\right)-c_{i} \\
& =\frac{(1+n) \beta}{9}-c_{i}, \quad i=A, B .
\end{aligned}
$$

\footnotetext{
${ }^{12}$ We show below that this is not the only case where investing is the optimal strategy. It can arise as a prisoners' dilemma.
} 


\section{When does the equilibrium have mixed strate- gies?}

It is helpful first to collect the above findings under pure strategies, with $c$ pointing to the cost of the investing firm,

$$
\begin{gathered}
\pi_{H}^{H L}=\frac{(\beta+b)^{2}(1+n)}{9 \beta}-c \\
\pi_{L}^{H L}=\frac{(\beta-2 b)^{2}(1+n)}{9 \beta} \\
\pi_{H}^{H H}=\frac{(1+n) \beta}{9}-c \\
\pi_{L}^{L L}=\frac{1}{9} \frac{(\beta-b)^{2}}{\beta} .
\end{gathered}
$$

Recalling, for the mixed strategy to appear in equilibrium, we must have

$$
\frac{\partial E\left[\pi_{A}\right]}{\partial q_{A}}=0, \frac{\partial E\left[\pi_{B}\right]}{\partial q_{B}}=0 .
$$

Consider now the case of firm $B$. For $q_{B}<1$, we must have that ${ }^{13}$

$$
\frac{\left(\pi_{A}^{H H}-\pi_{A}^{L H}\right)}{\left(\pi_{A}^{H L}-\pi_{A}^{L L}\right)}<0 .
$$

This condition holds in two exclusive cases.

(i) Case 1

$$
\pi_{A}^{H H}-\pi_{A}^{L H}>0 \& \pi_{A}^{H L}-\pi_{A}^{L L}<0 .
$$

It now becomes important to exlicitly differentiate the investment costs. Evaluating the first condition,

$$
\pi_{A}^{H H}-\pi_{A}^{L H}=\frac{(1+n) \beta}{9}-c_{A}-\frac{(\beta-2 b)^{2}(1+n)}{9 \beta}>0
$$

\footnotetext{
${ }^{13}$ We notice that when this condition is satisfied, $q_{B}$ is always positive.
} 
or,

$$
c_{A}<\frac{(1+n) 4 b(\beta-b)}{9 \beta} .
$$

Evaluating the second condition,

$$
\pi_{A}^{H L}-\pi_{A}^{L L}=\frac{(\beta+b)^{2}(1+n)}{9 \beta}-c_{A}-\frac{1}{9} \frac{(\beta-b)^{2}}{\beta}<0,
$$

or,

$$
c_{A}>\frac{(\beta+b)^{2} n}{9 \beta}+\frac{4 b}{9} .
$$

Combining,

$$
\frac{(\beta+b)^{2} n}{9 \beta}+\frac{4 b}{9}<c_{A}<\frac{(1+n) 4 b(\beta-b)}{9 \beta} .
$$

This can never hold, because for any reasonable parameter values the value of the left-hand side exceeds the value of the right-hand side.

(ii) Case 2

$$
\pi_{A}^{H H}-\pi_{A}^{L H}<0 \& \pi_{A}^{H L}-\pi_{A}^{L L}>0
$$

These conditions amount to stating

$$
\begin{gathered}
\frac{(1+n)^{2} \beta^{2}-((\beta-2 b)(1+n))^{2}}{9(1+n) \beta} \\
<c_{A}<\frac{((\beta+b)(1+n))^{2}}{9(1+n) \beta}-\frac{1}{9} \frac{(\beta-b)^{2}}{\beta}
\end{gathered}
$$

We have proved:

Proposition 2. The necessary and sufficient condition for a mixed strategy as an optimal choice for firm $B$ is that the cost of investment of its rival, firm A, satisfies the above conditions (22).

Corollary 2: Pure strategies can be played by firm B only if 


$$
c_{A}<\frac{(1+n)^{2} \beta^{2}-((\beta-2 b)(1+n))^{2}}{9(1+n) \beta} \text { or if } c_{A}>\frac{((\beta+b)(1+n))^{2}}{9(1+n) \beta}-\frac{1}{9} \frac{(\beta-b)^{2}}{\beta} \text {. }
$$

As the mixed strategies do not always exits in equilibrium, it makes sense to further study the pure strategies i.e. when $c_{A}$ does not satisfy any of the above two conditions.

Pure strategies in the limit Consider the optimal strategies when $c_{A}$ approaches its limits. In the limiting cases, when $c_{A} \rightarrow_{+} \underline{c}=\frac{(1+n)^{2} \beta^{2}-\left((\beta-2 b)(1+n)^{2}\right.}{9(1+n) \beta}$, we have $\left(\pi_{A}^{H H}-\pi_{A}^{L H}\right)=0$. Similarly, when $c_{A} \rightarrow \bar{c}_{-}=\frac{((\beta+b)(1+n))^{2}}{9(1+n) \beta}-\frac{1}{9} \frac{(\beta-b)^{2}}{\beta}$, we have that $\left(\pi_{A}^{H L}-\pi_{A}^{L L}\right)=0$. Linking with the expression for $q_{B}$, we have

$$
\lim _{c \rightarrow \underline{c}} q_{B}=1, \lim _{c \rightarrow \bar{c}} q_{B}=0 .
$$

Similarly for $q_{A}$.

We conclude that the firms do not always choose to play a mixed strategy. For the equilibrium to have mixed strategies, it is necessary that the conditions (22) are satisfied. These conditions link the value of consumer signalling with the firms' cost of being ethical. Ethical behavior may arise as a pure strategy but only if the cost of investment falls within an intermediate region. It cannot be too high but neither can it be too low. We turn now to focus on that possibility.

\section{Ethical behavior as a prisoners' dilemma: low profit equilibrium.}

An argument developed by Shleifer (2004) suggests that competition is detrimental to corporate ethics. Our analysis challenges his view. We arrive at this view by examining whether there exists a combination of pure strategies which satisfies the conditions for the prisoners' dilemma. This amounts to claiming that, in the absence of commitment, a low-profit equilibrium with both firms investing replaces a joint profit maximization where neither invests. Both firms would indeed generate more profits by not investing. However, in the face of a rival investing, it becomes optimal to follow the lead. In the current model, such a harsh requirement appears reasonable as otherwise the firms lose all the boycotting customers. 
Intuitively, the equilibrium depicting a prisoners' dilemma can be characterized by the conditions

$$
\pi_{A}^{H H}<\pi_{A}^{L L}, \pi_{B}^{H H}<\pi_{B}^{L L}, \pi_{A}^{H L}>\pi_{A}^{L L}, \pi_{B}^{H L}<\pi_{B}^{L L} .
$$

The condition $\pi_{A}^{H L}>\pi_{A}^{L L}$ indicates that if $A$ invests it can increase its profit subject to the condition that $B$ does not invest. The condition $\pi_{B}^{H L}<$ $\pi_{B}^{L L}$ indicates that in such a case $B$ will lose a lot.

In terms of the optimal strategies, the strategy pair $H H$ arising as a prisoners' dilemma requires that $q_{A}=q_{B}=1$. That is, it should be optimal to have the $H H$-equilibrium when the firms optimize individually,

$$
\frac{\partial E\left[\pi_{A}\right]}{\partial q_{A}}>0, \frac{\partial E\left[\pi_{B}\right]}{\partial q_{B}}>0 .
$$

Evaluating, $\frac{\partial E\left[\pi_{A}\right]}{\partial q_{A}}>0$, gives

$$
q_{B}\left(-\pi_{A}^{H H}+\pi_{A}^{L H}+\left(\pi_{A}^{H L}-\pi_{A}^{L L}\right)\right)<\pi_{A}^{H L}-\pi_{A}^{L L} .
$$

Given that the incentive to deviate from the $L L$-outcome exists for both firms, $\pi_{A}^{H L}>\pi_{A}^{L L}$, the right-hand side is positive. It is then sufficient for this inequality to hold that $-\pi_{A}^{H H}+\pi_{A}^{L H}<0$ which amounts to

$$
\pi_{A}^{L H}<\pi_{A}^{H H}
$$

representing one of the characterizations of the prisoners' dilemma. We now examine what conditions are required for the equilibrium to be characterized as prisoners' dilemma given the structure of our model.

First, when a firm, say $A$ switches individually from the strategy pair $L L$ to $H L$ while the other firm plays $L$, the profit of firm $A$ increases,

$$
\frac{((\beta+b)(1+n))^{2}}{9(1+n) \beta}-c_{A}>\frac{1}{9} \frac{(\beta-b)^{2}}{\beta} .
$$

Second, the profit of the firm, say $B$ is reduced if it does not follow, that is

$$
\frac{((\beta-2 b)(1+n))^{2}}{9(1+n) \beta}<\frac{1}{9} \frac{(\beta-b)^{2}}{\beta} .
$$

Third, the profits are lower under the strategy pair $H H$ than under the strategy pair $L L$,

$$
\frac{(1+n) \beta}{9}-c_{i}<\frac{1}{9} \frac{(\beta-b)^{2}}{\beta}, \quad i=A, B .
$$


Fourth, the profits cannot be negative when the strategy pair $H H$ is chosen,

$$
c_{i}<\frac{(1+n) \beta}{9} .
$$

Multiplying the condition (26) by $(1+n)$,

$$
((\beta-2 b)(1+n))^{2}<(\beta-b)^{2}(1+n)
$$

shows that this is likely satisfied. Consider the rest of the conditions to be combined as

$$
\begin{gathered}
\frac{(1+n) \beta}{9}-\frac{1}{9} \frac{(\beta-b)^{2}}{\beta}<c_{i}< \\
\min \left(\frac{((\beta+b)(1+n))^{2}}{9(1+n) \beta}-\frac{(\beta-b)^{2}}{9 \beta}, \frac{(1+n) \beta}{9}\right), \quad i=A, B .
\end{gathered}
$$

It remains to give a numerical example as to when these conditions can hold. Take $\beta=1$. Moreover, it makes sense to examine the limiting case $n \rightarrow 0$. The lower limit for $c_{i}$ then becomes

$$
\frac{1}{9} b(2-b)<c_{i} .
$$

For example, having then $b=0.25$, one obtains

$$
0.0486<c_{i} \text {. }
$$

Now the upper limit,

$$
c_{i}<\min \left(\frac{(1+b)^{2}}{9}-\frac{(1-b)^{2}}{9}, \frac{1}{9}\right)
$$

With $b=0.25$, one has

$$
\begin{aligned}
c_{i} & <\min (0.11,0.11) \\
& =0.11 .
\end{aligned}
$$

Thus, when the investment satisfies

$$
0.0486<c_{i}<0.11,
$$

the $H H$ strategy pair may arise as a prisoners' dilemma, provided that it is not optimal to play a mixed strategy studied earlier. From there we know that a mixed strategy cannot arise in equilibrium if 


$$
c_{i}<\frac{(1+n)^{2} \beta^{2}-((\beta-2 b)(1+n))^{2}}{9(1+n) \beta} .
$$

With the numerical values above, this condition is

$$
c_{i}<\frac{1-((1-0.5))^{2}}{9}=0.083 \text {. }
$$

Indeed, when $0.0486<c_{i}<0.083$, the equilibrium arises as a prisoners' dilemma. This conclusion was strictly obtained by having the number of moral consumers in the market $n=0$. By continuity, it must hold also when $n$ is positive but sufficiently small. We can state the conclusion as a proposition:

Proposition 3: When the number of moral consumers is small and when the investment cost is small but strictly positive, firms may invest in abatement even if their profits are reduced. The equilibrium then arises from a prisoners' dilemma.

Were $c_{i}<0.0486$, the $H H$ equilibrium would arise as a dominating pure strategy not as a prisoners' dilemma. For completeness, it is worth stating that when the investment $\operatorname{cost} c_{i}$ is high, say $c_{i}>\bar{c}$, the $L L$ becomes the dominating strategy.

\section{Final remarks}

Modern communication media, including the internet, enhance the opportunities for consumers to influence the ethical behavior of producers. This increased influence has induced firms to devote substantial effort to build a favorable image among consumers. Consumer power apparently has been increasing and will continue to increase though we only have indirect evidence on that. Firms often highlight their contributions to economic development or to environmental quality. Consequently, with increasing concern about environmental issues like the greenhouse effect, one can expect that we will see an increased incentive for individuals to organize boycotts in the future. In the end, there may be fewer, however, if such a threat leads firms to behave better. 
Do markets produce the right amount of boycotts? Are there too few boycotts from the social point of view? This is a challenging welfare issue. In an individualistic society with utilitarian preferences, the well-being of (all) citizens are often taken as the starting point for the evaluation of the social welfare. Boycotts enhance the market position of well-behaving firms and the consumer surplus of their customers. There are, however, quite a few other welfare aspects. The negative externalities, say pollution, is reduced - we have not modelled such an externality explicitly. The moral individuals who abstain from buying from the unethical firm do benefit, though we abstracted from introducing this mechanism in our formal model if only to simplify. By implication, the immoral consumers who for the reasons of opportunism switch the firm tend to cause a positive externality on the moral ones. Such a positive externality tends, however, to be diluted if the private return on signalling a moral characteristic suffers from the number of boycotters. Organizing a boycott, however, can be socially costly as it represents a reduction in use of resources in a productive activity. People who bear these costs may not be the same people who benefit from boycotts as some are free-riders and can take opportunistically the advantage of lower prices of the products boycotted. Those less moral individuals who buy from the unethical firm suffer a cost as they definitively are now separated from the moral ones.

\section{References}

[1] Andersen, T., (1999) "Consumer Power via the Internet". Available at http://www.firstmonday.org/issues/issue4_1/andresen/index.html

[2] Antheon, C., Camarero, C. and Carrero, M., (2007) "Analyzing firms' failures as determinants of consumer switching intentions: The effect of moderating factors." European Journal of Marketing, 41, 135-158.

[3] Baron, D.P., (2002) "Private Politics and Private Policy: A Theory of Boycotts." Stanford Graduate School of Business.

[4] Binmore, K., (1998) Game Theory and the Social Contract II. Just playing, Cambridge: MIT Press.

[5] Blackmore, S., (1999) The Meme Machine, Oxford: Oxford University Press. 
[6] Cronberg, T., (1986) "Consumer influence on new technology-Real potential or false hopes?" Journal of Consumer Policy, 9, 335-343.

[7] Dawkins, R., (1976) The Selfish Gene.

[8] Diamond, J., (2005) Collapse. How Societies Choose to Fail or Survive, Penguin Books.

[9] Florida, Richard (1996) "Lean and green: The move to environmentally conscious manufacturing." California Management Review, 39: 80-105.

[10] Folkes, V.S., (1999) "Effects of Information About Firm's Ethical and Unethical Actions on Consumers' Attitudes", Journal of Consumer Psychology, 8, 243-259.

[11] Friedman, M. (1970) "The Social Responsibility of Business is to Increase Its Profits", New York Times Magazine, 13 September, 1970.

[12] Güth, W., (1993) "A Simple Justification of Quantity Competition and the Cournot-Oligopoly Solution", Center for Economic Research, Tillburg University, Paper N:o 9305.

[13] Innes, R. A. (2006) "A Theory of Consumer Boycotts under Symmetric Information and Imperfect Competition." Economic Journal, 116: 355381.

[14] John, A., Klein, J.K., and Smith, N.C., (2002) "Exploring Motivations for Participation in a Consumer Boycott", Advances in Consumer Research, 29: 363-369.

[15] Kanniainen, V., and Pietarila, E., (2006) "Corporate Social Responsibility: Can Markets Control?" Homo Oeconomicus, 23: 153-179.

[16] Klein, J.K., Smith, N.C., and John, A. (2004) "Why We Boycott: Consumer Motivations for Boycott Participation", Journal of Marketing, 68, 92-109.

[17] Klemperer, P., (1995) "Competition when Consumers have Switching Costs: An Overview with Applications to Industrial Organization, Macroeconomics, and International Trade." Review of Economic Studies $62,515-539$. 
[18] Kreps, D., and Scheinkman, J., (1983) "Quantity Precommitment and Bertrand Competition Yield Cournot Outcomes." Bell Journal of Economics, 14, 326-337.

[19] Morales, A.C., (2005) "Giving Firms and "E" for Effort: Consumer Responses to High-Effort Firms." Journal of Consumer Research, 312: 806-812.

[20] Shleifer, Andrei, (2004) "Does Competition Destroy Ethical behavior?" American Economic Review Papers and Proceedings, 94: 414-418. 